\title{
Astronomical phenomena: events with high impact factor in teaching optics and photonics
}

Dan Curticapean

Dan Curticapean, "Astronomical phenomena: events with high impact factor in teaching optics and photonics," Proc. SPIE 9289, 12th Education and Training in Optics and Photonics Conference, 928909 (17 July 2014); doi:

$10.1117 / 12.2070281$

SPIE Event: 12th Education and Training in Optics and Photonics Conference, 2013, Porto, Portugal 


\title{
Astronomical phenomena: Events with high impact factor in teaching Optics and Photonics
}

\author{
Dan Curticapean ${ }^{1}$ \\ ${ }^{1}$ University of Applied Sciences Offenburg, Germany, dan.curticapean@hs-offenburg.de \\ Keywords: 000.2060 Educations, Education in Optics and Photonics, Astronomical events
}

\begin{abstract}
Astronomical phenomena fascinate people from the very beginning of mankind up to today. They have a enthusiastic effect, especially on young people. Among the most amazing and well-known phenomena are the sun and moon eclipses. The impact factor of such events is very high, as they are being covered by mass media reports and the Internet, which provides encyclopedic content and discussion in social networks.
\end{abstract}

The principal optics and photonics topics that can be included in such lessons originate from geometrical optics and the basic phenomena of reflection, refraction and total internal reflection. Lenses and lens systems up to astronomical instruments also have a good opportunity to be presented. The scientific content can be focused on geometrical optics but also diffractive and quantum optics can be incorporated successfully.

The author will present how live streams of the moon eclipses can be used to captivate the interest of young listeners for optics and photonics. The gathered experience of the last two moon eclipses visible from Germany (on Dec, 212010 and Jun, 15 2011) will be considered. In an interactive broadcast we reached visitors from more than 135 countries.

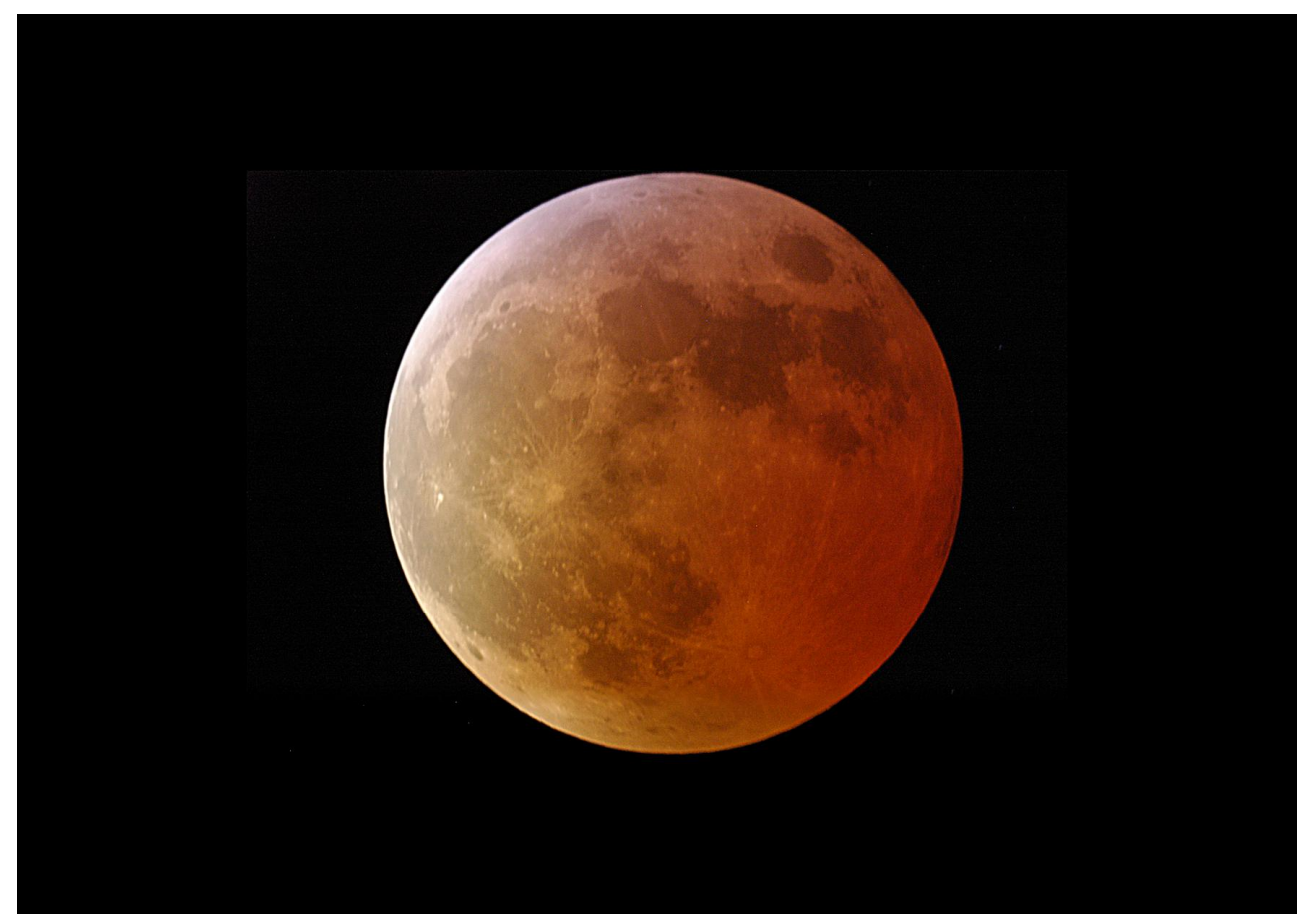

Figure 1: Total Moon eclipse 2007 over Offenburg, Germany. Photography by author

12th Education and Training in Optics and Photonics Conference, edited by

Manuel F. P. C. Martins Costa, Mourad Zghal, Proc. of SPIE Vol. 9289, 928909

(C) 2014 SPIE, OSA, IEEE, ICO·doi: 10.1117/12.2070281 


\section{LUNAR ECLIPSES - THEORETICAL CONSIDERATIONS}

Lunar eclipses (Figure 1) are very impressive natural events and have entered ancient mythologies as they are quite rare, make the moon appear unnaturally red and have a relatively long duration.

Total lunar eclipses always occur when the Sun, Earth and Moon (in this order) are aligned in a straight line. Lunar eclipses always occur at full moon since the moon must cross the node position exactly at full moon [1] - [2].

\section{Geometry of the moon umbra}

The umbra geometry of Sun, Earth and Moon is the key to understanding lunar eclipses. Considering the positions of Sun and Earth, the umbra is a cone with a length of 1.4 million $\mathrm{km}$ and a radius of ca. $4500 \mathrm{~km}$ at the moon orbit. This geometry provides a particular characteristic for lunar eclipses, which is called the magnitude (or totality). It is defined as the ratio between the immersion depth in the umbra and the moon radius. Therefore, lunar eclipses can have more than $100 \%$ magnitude. The maximal totality is at about $188 \%$ (see literature) [3]. A lunar eclipse can last up to three hours, of which it can be in totality for approximately 1 hour 40 minutes [3]. The geometry of the moon penumbra is a divergent cone, expanding into space.

Considering the particular of umbra and penumbra, we can distinguish three types of lunar eclipses [1] - [7]:

Total lunar eclipse: The moon occurs during the darkness completely into the umbra of the earth.

Partial lunar eclipse: Only a part of the moon is covered by Earth's umbra, the remaining part is still in the penumbra.

Partial penumbral eclipse: The moon appeared only partially into the penumbra.

Total lunar penumbra eclipses are almost impossible. In this setting, the moon should appear only in the penumbra of the earth and not in the umbra. Such total penumbral eclipses are extremely rare because the ring of the penumbra is approximately as wide as the diameter of the moon.

\section{Moments or Phases during a total lunar eclipse (Figure 2) [4], [7]}

Contact 1 - Penumbral lunar eclipse begins

Contact 2 - Partial umbral lunar eclipse begins

Contact 3 - Total umbral lunar eclipse begins

Contact 4 - Maximal umbral lunar eclipse magnitude

Contact 5 - Total umbral lunar eclipse ends

Contact 6 - Partial umbral lunar eclipse ends

Contact 7 - Penumbral lunar eclipse ends

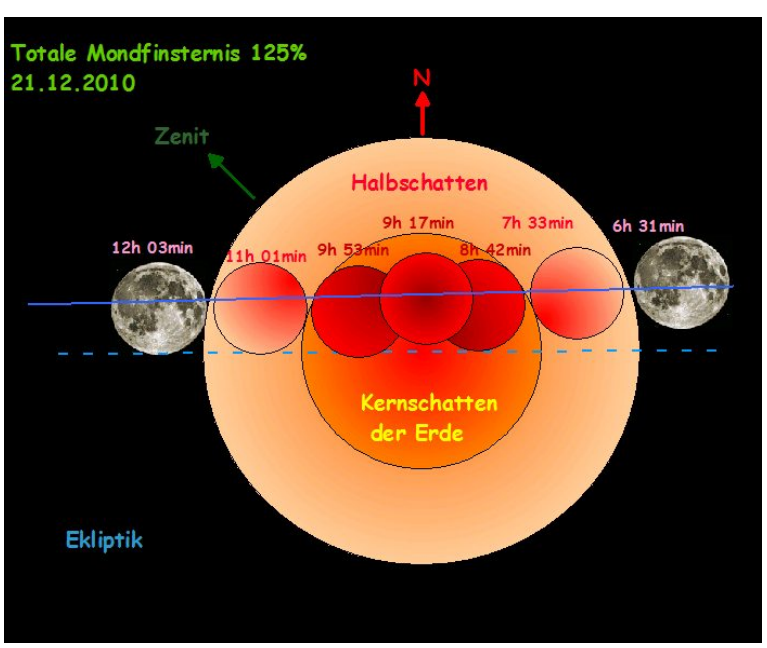

Figure 2a: Moments of the lunar eclipse 21.12.2010 [7]

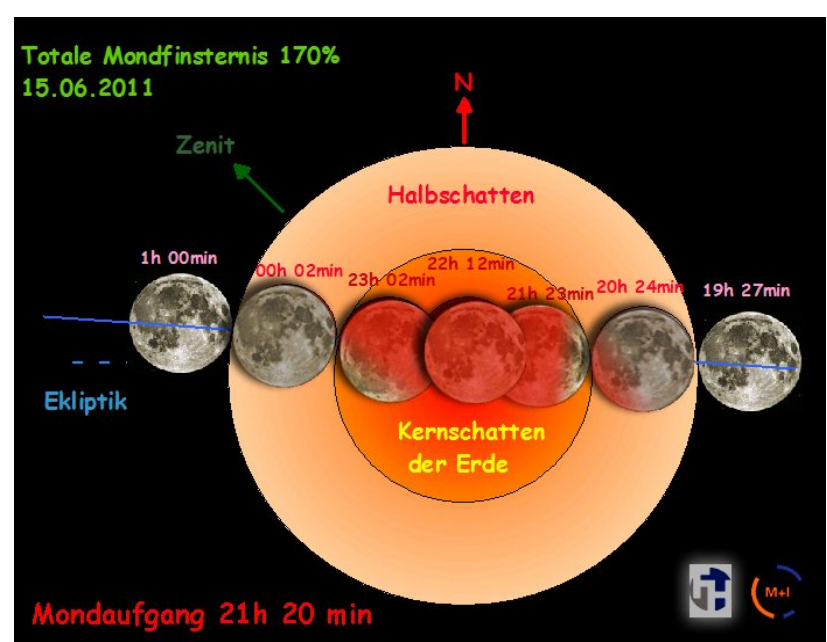

Figure 2b: Moments of the lunar eclipse 15.06.2011 [7] 
As mentioned before, the moon appears red or orange-red during the totality phase. This effect, which is an impressive spectacle of nature, is caused by Earth's atmosphere. Two phenomena are responsible for this effect: On one hand, Earth's atmosphere acts like a lens, and on the other hand, the molecules in Earth's atmosphere scatter short wavelength light (green, blue) more than light of long wavelength (red).

To evaluate the brightness of lunar eclipses, a measurement scale was introduced by the French astronomer Danjon. This scale comprises five different values.

Danjon Scale (see definitions [4], [5])

$\mathbf{L}=\mathbf{0}$ - "Very dark eclipse (Moon is almost invisible, especially at mid-totality)" [4], [5]

$\mathbf{L}=\mathbf{1}$ - "Dark eclipse, gray or brownish in coloration (Details are distinguishable only with difficulty)" [4], [5]

$\mathbf{L}=\mathbf{2}$ - "Deep red or rust-colored eclipse (Very dark central shadow, while outer umbra is relatively bright)" [4], [5]

$\mathbf{L}=\mathbf{3}$ - "Brick-red eclipse (Umbral shadow usually has a bright or yellow rim)" [4], [5]

$\mathbf{L}=4$ - "Very bright copper-red or orange eclipse (Umbral shadow has a bluish, very bright rim)" [4], [5]

The Danjon Scale can also be considered as a measure of the purity of the Earth's atmosphere. For instance, lunar eclipses in years with numerous or heavy volcanic eruptions are very dark and black, yielding lunar eclipses with $\mathrm{L}$ values of 0 or 1 .

There are more solar eclipses than lunar eclipses. However, solar eclipses are confined to their comparatively small visibility regions, whereas every lunar eclipse can be witnessed from one half of Earth's surface. Thus, lunar eclipses subjectively appear to be more frequent. [8] - [9]

\section{ORIGIN OF THE IDEA}

The idea of broadcasting solar and lunar eclipses live in the internet was born after the total solar eclipse over Europe on August 11, 1999, when the world-wide web was still in its infancy. The solar eclipse sparked an unforeseen enthusiasm from young people, who even soaked up its scientific backgrounds eagerly. We wanted to harness this enthusiasm to create an informative educational show about astronomical events that could be viewed by people from all over the world.

However, given the limited possibilities of broadcasting multimedia content in last century's internet, i.e., six whole years before the advent of websites like YouTube, the idea of streaming astronomic events live on-line had to be approached in baby steps. Our team had to deal with many technical obstacles, which was even more delicate since the next (lunar) eclipse was only five months away.

After assembling a first set of informative material, we programmed the website www.eclipse-live.com and launched it. Video streaming capabilities were installed and various technical problems were solved, sometimes in an improvised manner. Then, on January 21, 2000, we had finally transformed a lab and a hallway of our university into a broadcasting station. Our team, which was consisting of ten people at this time, was simmering with excitement in view of the nearing eclipse.

But to our great disappointment, it was raining the whole day and the whole night. Therefore, we could not catch a clear view of the moon with our telescopes, and this was particularly disappointing since several local radio stations were featuring us in live connections. The event seemed like a failure.

Swallowing our anger, we evaluated the traffic logs on the next day. And, to our great surprise, we observed that more than 2000 visitors from 20 countries watched our mostly improvised broadcast. In view of our meager advertisement, which we did not expect to reach so far, we were particularly surprised and delighted about a visitor from Brazil. Another surprise was that our website was now featured as the leading result for the search term "Mondfinsternis", the German word for "lunar eclipse", on the search engine Yahoo. (Note that, back then, even Google was not yet very popular.) And all this happened even though the moon, the main "star" in our show, was manqué. After this experience, we were definite about continuing the endeavor. 


\section{SCIENTIFIC AND TECHNICAL IMPLEMENTATION}

After ten years, in which we collected further experience in broadcasting lunar eclipses, we realized that our project requires a new concept and broadcast format to be future-proof. Together with students who wanted to work on the topic of live broadcasting, we therefore developed a new concept for the upcoming lunar eclipses on December 21, 2010 and June 15, 2011. While planning the new shows, the following aspects were incorporated: Advertisement, scientific background, a new internet presence including a redesigned homepage, enabling interactivity with our visitors, and storing and publishing the stream in a way that it can be watched asynchronously.

\section{Goals of the Event}

The goals we set up for the project were ambitious, yet realistic. Concerning the technical side, we wanted to improve the stream to HD resolution. From an editorial perspective, we wanted to compose an "edutaining" show that blends an informational purpose with entertaining elements. Thus, we wanted to convey a sensible amount of information about aspects of lunar eclipses, such as their origin, length, and the different types of lunar eclipses. This background information should serve to arouse the viewers' interest in astronomy. Furthermore, one of our most important goals was to increase our outreach to viewers from all over the world.

The media planning of the lunar eclipse was focused on the following aspects:

- Advertising

- Scientific background

- New website

- Broadcast of Evnents

\section{Advertising}

As appropriate local advertising, posters (Fig. 3) were prepared for the campus of our university and its surrounding area. Online versions of the poster were made available as PDFs for download on the website. Local press and mass media were informed and asked to report about our intention. Furthermore, links were placed in search engines and on Wikipedia.

\section{Scientific background}

To emphasize the scientific aspect of the event [10] - [11], the following measures have been prepared in advance:

- Scientific video clips (topics: planetariums, galileoscopes)

- Flash animations

During the broadcast, presentations on the following topics were held in layman's terms:

- Lunar eclipses

- History of the moon [8] - [9]

- Cosmic velocities

- Measurements of astronomical distances [1] - [2]

- Gravitational Waves [13] - [14]

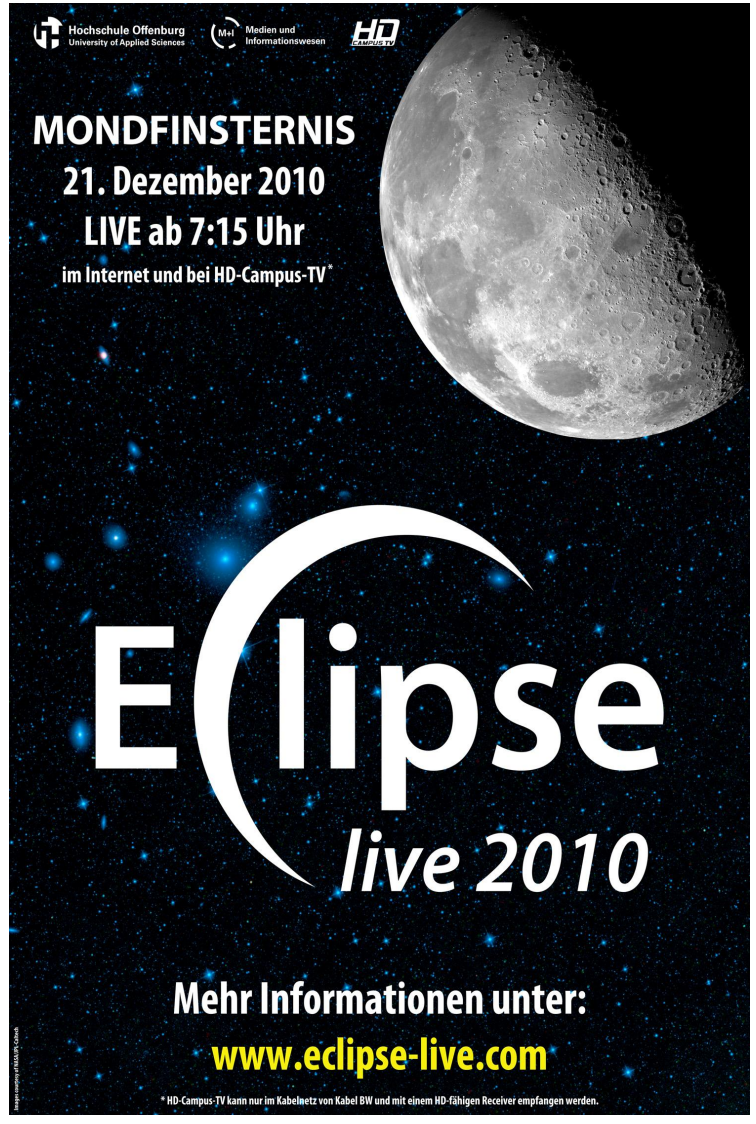

Figure 3: Lunar eclipse advertising poster [4] 


\section{New website}

The new website (Fig. 4) was developed with the help of new web technologies. A contemporary design was created. The performance had to support the new requirements, such as a sufficient bandwidth for coping with HD streaming and the expected high visitor traffic.

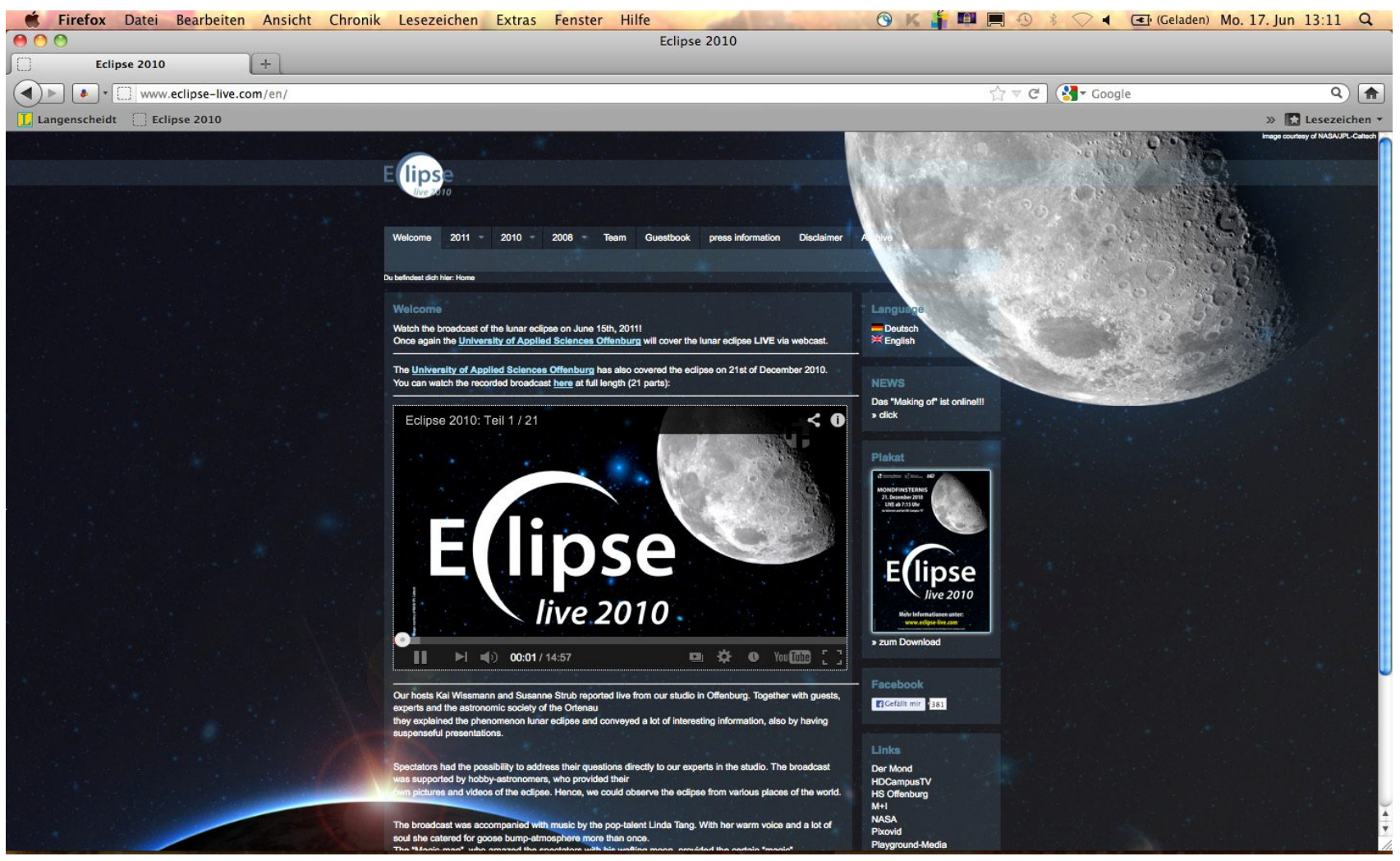

Figure 4: Eclipse live - New website

\section{Broadcast of Evnents}

For the live broadcast, a studio was set up whose setting was chosen so as to resemble the solar system. The scenography can be seen in Figure 5. A screen in the background supplied information about the progress of the lunar eclipse and was also used to display a feed to our outdoor setup on the roof of the building. A blackboard in the studio enabled sketches and simple calculations. The show was moderated by an anchorman, who spoke German, and an anchorwoman, who spoke English and addressed our international viewers.
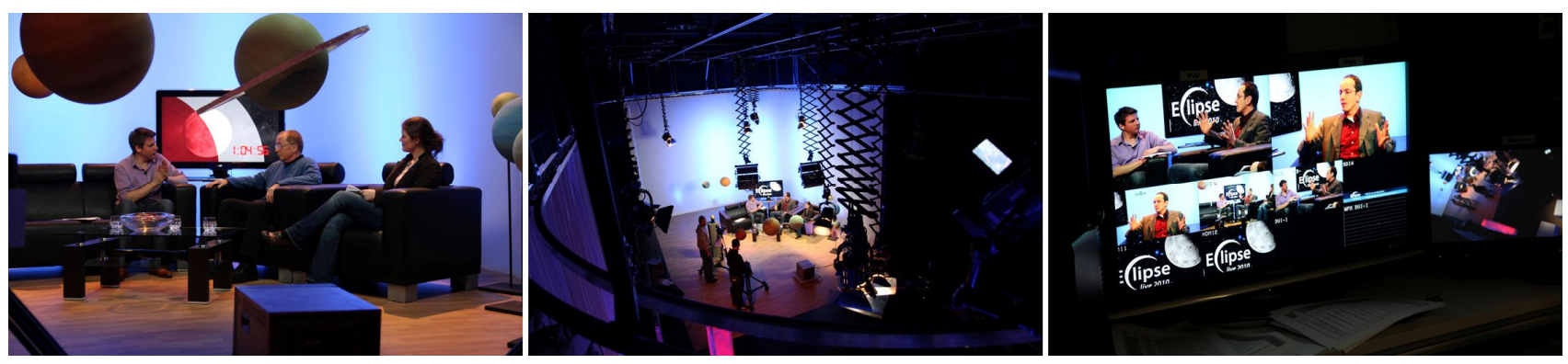

Figure 5: Eclipse live 2010 - Scenography and production area 
Three video cameras were set up in the studio, and a fourth camera was put on the roof to capture outdoor footage. The moon was recorded with a Canon 5D Mark II that had a MEADE LXD75 [12] Schmitt-Cassegrain telescope $\left(8^{\prime \prime}, \mathrm{F}=2000 \mathrm{~mm}, \mathrm{f} / 10\right)$ attached as a lens (Fig. 6).
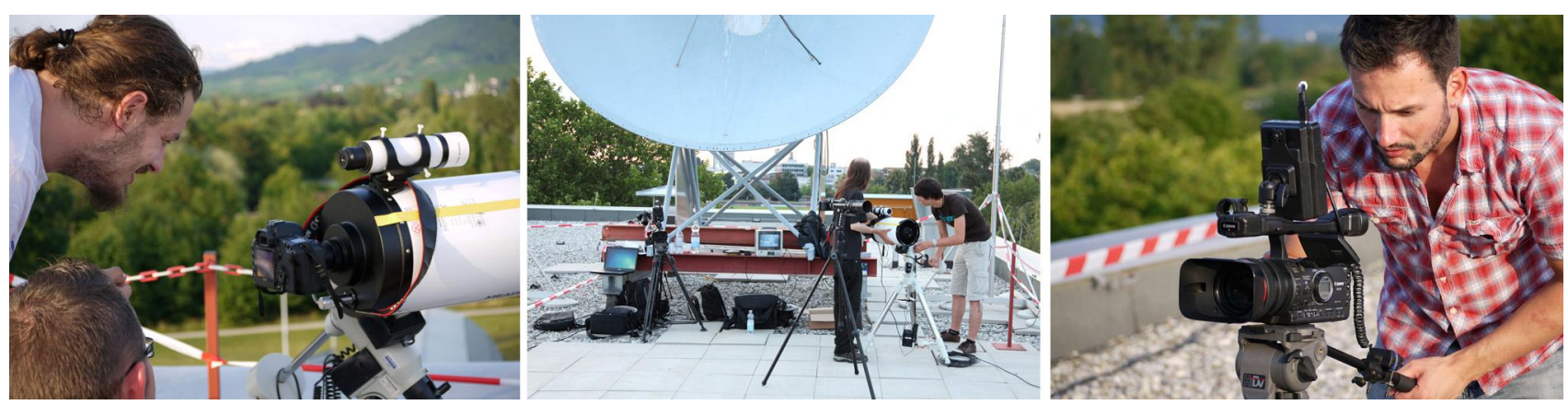

Figure 6: Eclipse live 2011 - Recording cameras and MEADE LXD75 telscope

The cameras supplied video signals to the production where they were processed and prepared for live streaming. Via a live-stream server, the video signal was converted to an internet-ready stream that was then forwarded to the Amazon Wowza Media Server, from where the stream was then distributed worldwide. A second signal was routed to a local television cable.

To cope with the large amount of viewers, up to seven servers were used during the live broadcast. The production area also housed the editorial team, responsible for coordinating the course of action and the content. The previously prepared contributions could be patched in into the stream by the editorial team at scheduled times. Furthermore, we also included live video chats via Skype into the show.

After the broadcast, we evaluated the traffic data captured by Google Analytics [16] to enable better preparation of future broadcasts.

\section{RESULTS AND EVALUATION}

We produced a live broadcast in HD and streamed in HD. For our technical possibilities, this was a premiere. The reactions exhibited by viewers were positive. By recording the live stream and publishing it on the website, we enabled viewers to watch parts again, or watch missing parts (video on demand VoD). Furthermore, we were able to ensure that our viewership was not limited to live viewers.

Although the moon was visible for only a few minutes from our location during the lunar eclipses in 2010 and 2011, we considered the broadcasts a success. In 2011, we counted over 35,000 viewers from 136 countries [16].

Figure 7 shows a world map with all countries that accessed our website. In Table Aa, some countries are listed together with the number of viewers from the respective country.

Figure 8 shows from which cities visitors accessed our website. The first 100 cities are listed with their numbers of visitors. Cities in bold letters are located outside of Germany.

In the Lunar eclipse live project were more than 50 students involved. We contacted over two hundert astronomical observatories. With some we could work together.

A digital Moonbook [15] was developed by our students and is available for download on your iPad with iBooks or on your computer with iTunes.

The next lunar eclipse in Offenburg will be on September 28, 2015. See you in 2015! 


\section{Karten-Overlipse-live.com/}

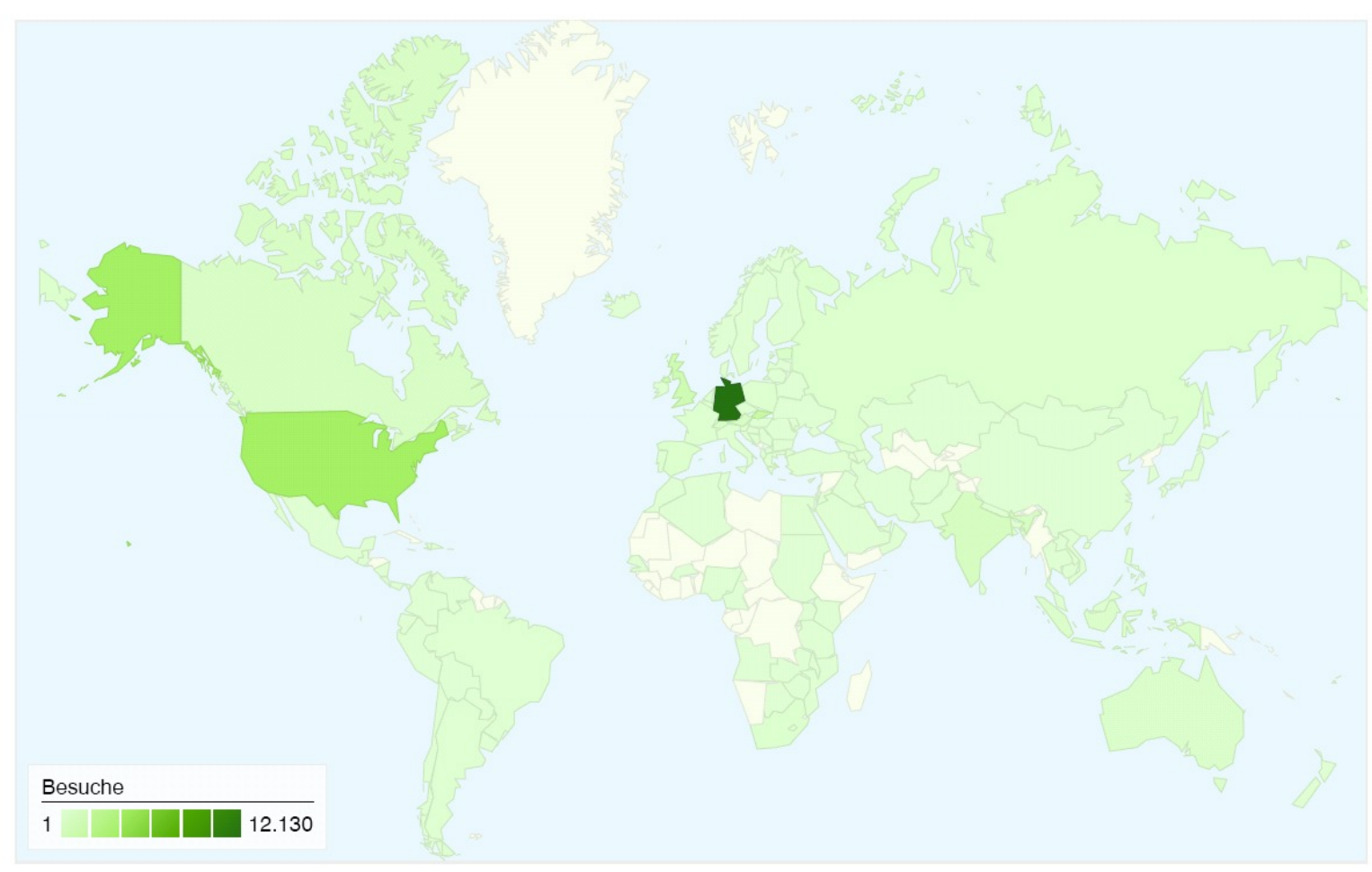

\subsection{Besuche wurden über 136 Länder/Gebiete vermittelt.}

Figure 7: Countries that accessed our website Lunar Eclipse 15.06.2011 (Graphics Google Analytics [16])

\section{Country}

1. Germany

2. United States

3. Slovakia

4. United Kingdom

5. India

6. Austria

7. Canada

8. Switzerland

9. Estonia

10. Australia

11. Indonesia

14. South Africa

15. Philippines

20. Singapore

24. Argentina

26. Malaysia

31. New Zealand

33. United Arab Emirates

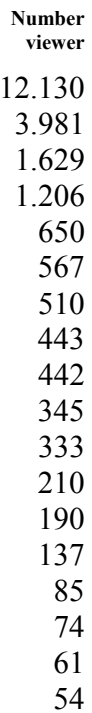

\section{Country}

38. Hong Kong

44. Thailand

47. Japan

48. Mauritius

56. Taiwan

57. Kenya

62. Vietnam

66. Sri Lanka

72. Trinidad and Tobago

76. Iran

81. Maldives

87. Fiji

90. Mozambique

96. Uganda

103. Senegal

118. Mongolia

135. Cambodia

136. Burkina Faso

$\begin{array}{r}\text { Number } \\ \text { viewer }\end{array}$
46
41
34
32
18
16
14
11
10
8
7
5
4
3
2
1
1
1

Table 1: Selected countries with the number of viewers from the respective country [16] 


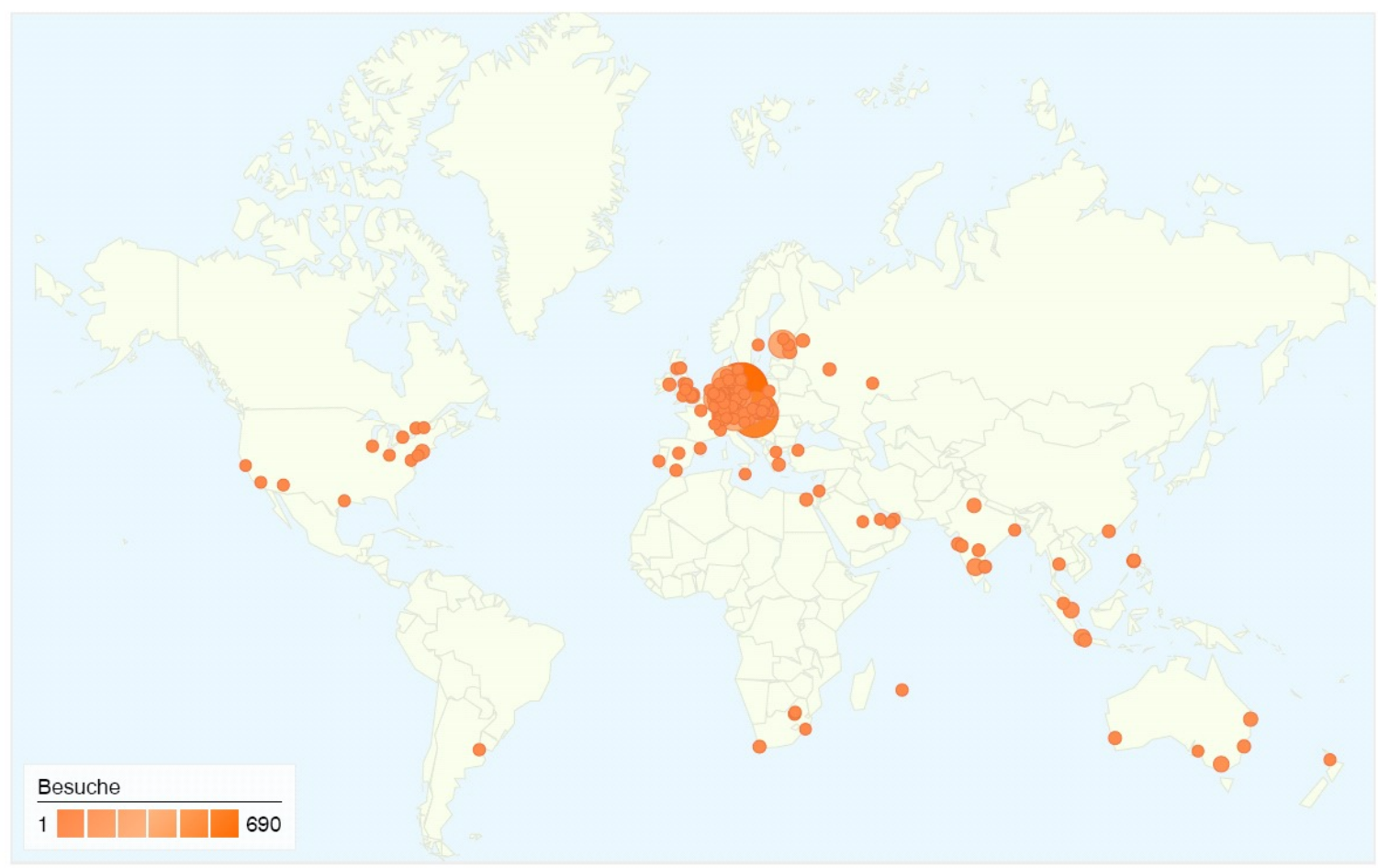

\subsection{Besuche wurden über 2.802 Städte vermittelt.}

Figure 8: Shows from which cities wolrdwide visitors accessed our website. (Graphics Google Analytics [16])

Berlin 690; Bratislava 592; Munich 374; Hamburg 373; Cologne 277; Tallinn 276; Stuttgart 248; Frankfurt am Main 215; Hannover 214; Karlsruhe 181; Vienna 168; Leipzig 164; Nuremberg 139; Dusseldorf 139; Dresden 139; Essen 137; Freiburg Im Breisgau 120; Dortmund 119; Bonn 115; Mannheim 109; Offenburg 105; Kosice 101; Bangalore 101; Bremen 99; Jakarta 92; Zurich 89; Munster 84; Kiel 83; London 82; Wolfenbuttel 81; Singapore 81; Bochum 79; Melbourne 77; Erfurt 69; Mainz 67; Topolcany 63; Oldenburg 63; New York 62; Chemnitz 61; Zilina 61; Duisburg 60; Darmstadt 60; Aachen 59; Magdeburg 58; Saarbrucken 56; Osnabruck 56; Augsburg 56; New Delhi 55; Brisbane 54; Ulm 53; Heilbronn 51; Wurzburg 51; Tartu 50; Kassel 50; Halle 48; Manila 48; Wuppertal 47; Heidelberg 47; Nitra 44; Gottingen 44; Bandung 42; Koblenz 42; St Petersburg 41; Paderborn 40; Trnava 40; Sydney 39; Mumbai 39; Wiesbaden 39; Cairo 38; Dublin 38; Moscow 37; Lubeck 37; Regensburg 37; Perth 36; Athens 36; Presov 35; Chennai 35; Rostock 35; Cape Town 35; Hong Kong 34; Graz 33; Flensburg 33; Ludwigsburg 32; Prievidza 32; Neuwied 31; Pune 30; Baden-Baden 30; Giessen 30; Jena 30; Hyderabad 30; Johannesburg 29; Monchengladbach 29; Konstanz 28; Trencin 26; Trier 26; Linz 26; Potsdam 26; Reutlingen 26

Tab. 2: First 100 cities with their numbers of visitors [16]; Cities in bold letters are located outside of Germany. 


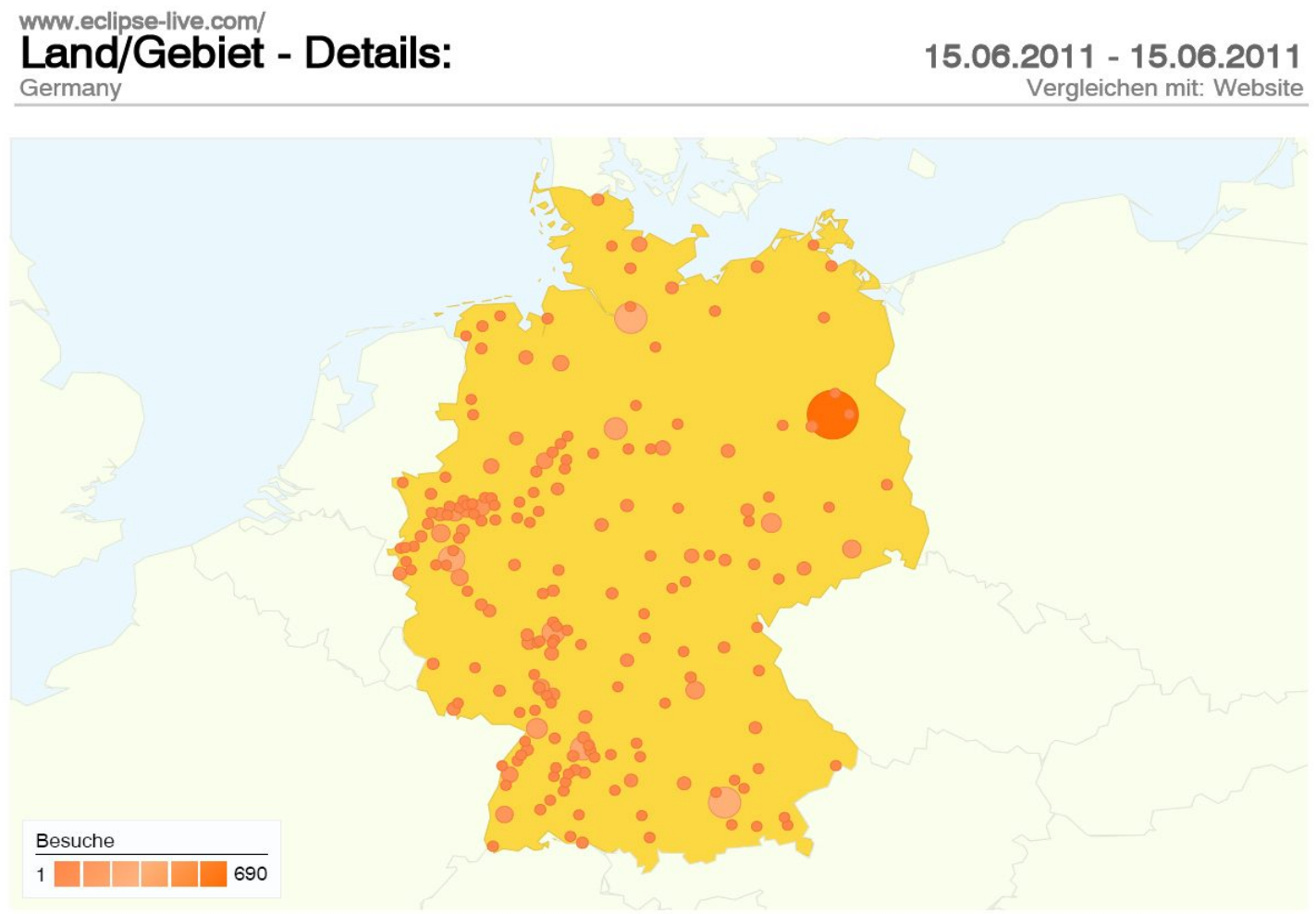

\section{Aus diesem Land/Gebiet kamen 8.085 Besuche über 591 Städte.}

Figure 9: Shows from which cities in Germany visitors accessed our website. (Graphics Google Analytics [16])

\section{REFERENCE}

[1] Bennett J., Donahue M., Schneider N., Voit M.: Astronomie - Die kosmische Perspektive, Pearson Education Deutschland GmbH, München 2010.

[2] Comins Neil F.: Astronomie, Spektrum Akademischer Verlag, Heidelberg, 2010.

[3] Bruno Deiss: Erläutereungen zu den Finsternisdaten; http://www.planetenkunde.de/p012/p01209/p0120903001.htm (June 11, 2013)

[4] Fred Espenak: NASA Eclipse Web Site; http://eclipse.gsfc.nasa.gov/LEdecade/LEdecade2011.html (June 10, 2013)

[5] Lunar Eclipse: http://en.wikipedia.org/wiki/Lunar_eclipse, (June 1, 2013).

[6] Mondfinsternis: http://de.wikipedia.org/wiki/Mondfinsternis, (June 1, 2013).

[7] Eclipse Live; www.eclipse-live.com (June 1, 2013).

[8] Der Mond: http://de.wikipedia.org/wiki/Mond, (June 1, 2013).

[9] Moon: http://en.wikipedia.org/wiki/Moon, (June 1, 2013).

[10] Dan Curticapean: Magic of Light; Optics Education and Outreach, Proc. of SPIE Vol. 7783, 77830I, doi: 10.1117/12.862847

[11] Dan Curticapean: University for Childern - The Magic of Light; Education \& Training in Optics \& Photonics; ST. Asaph, North Wales, UK, 2009

[12]***: MEADE - Instruction Manual LXD ${ }^{\mathrm{TM}} 75$ - Series Telescopes, Meade Instruments Corporation, 2004.

[13] Schilling Govert, Lindberg Christensen Lars: Unser Fenster zum Weltraum, WILEY-VCH Verlag GmbH \& Co. KGaA, Weinheim 2009.

[14] Lindberg Christensen Lars, Fosbury R., Hurt R.: Verborgenes Universum, WILEY-VCH Verlag GmbH \& Co. KGaA, Weinheim 2009.

[15] Cerkowniak A., Hermanns D., Nitsche N., Stöferle S., Wilke R.: Moonbook; https://itunes.apple.com/us/book/moonbook/id599565412?ls=1 (15.06.2013)

[16] Google Analytics for www.eclipse-live.com at 16.06.2011 
APPENDIX 1: MOON PARAMETERS [1]- [9]

$\begin{aligned} \text { Mass } & \begin{array}{l}7,34 \mathrm{10}^{22} \mathrm{~kg} \\ (1 / 81 \mathrm{Earth})\end{array} \\ \text { Radius } & 1738 \mathrm{~km} \\ \text { Volume } & 2197 \mathrm{~km}^{3} \\ & (1 / 50 \mathrm{Earth}) \\ \text { Surface area } & 3,79310^{7} \mathrm{~km}^{2} \\ & (1 / 13,5 \mathrm{Earth})\end{aligned}$

Distance to Earth

$\begin{aligned} \text { Apogee } & 406740 \mathbf{k m} \\ \text { Perigee } & 356410 \mathbf{k m} \\ \text { mean } & 384403 \mathbf{k m}\end{aligned}$

Distance to Sun

$\begin{aligned} \max & 15210^{6} \mathrm{~km} \\ \min & 14710^{6} \mathrm{~km} \\ & \\ \text { Age } & 4,6 \text { Billion years } \\ \text { ocity } & 2,38 \mathrm{~km} / \mathrm{s}\end{aligned}$

Temperature at the Equator

$\begin{aligned} \text { day } & 127^{\circ} \mathrm{C} \\ \text { night } & -173^{\circ} \mathrm{C}\end{aligned}$

Orbital period

siderial $\quad 27$ days $7 \mathrm{~h} \mathbf{4 3} \mathrm{min}$

synodical 29 days $12 \mathrm{~h} 44 \mathrm{~min}$

Mean Velocity $\quad 3700 \mathrm{~km} / \mathrm{h}$

Inclination to Ecliptic $\quad 5,145^{\circ}$

Albedo $\quad 0,12$ 


\section{APPENDIX 2: LIVE BROADCAST FROM THE WEBSITE (2010)}

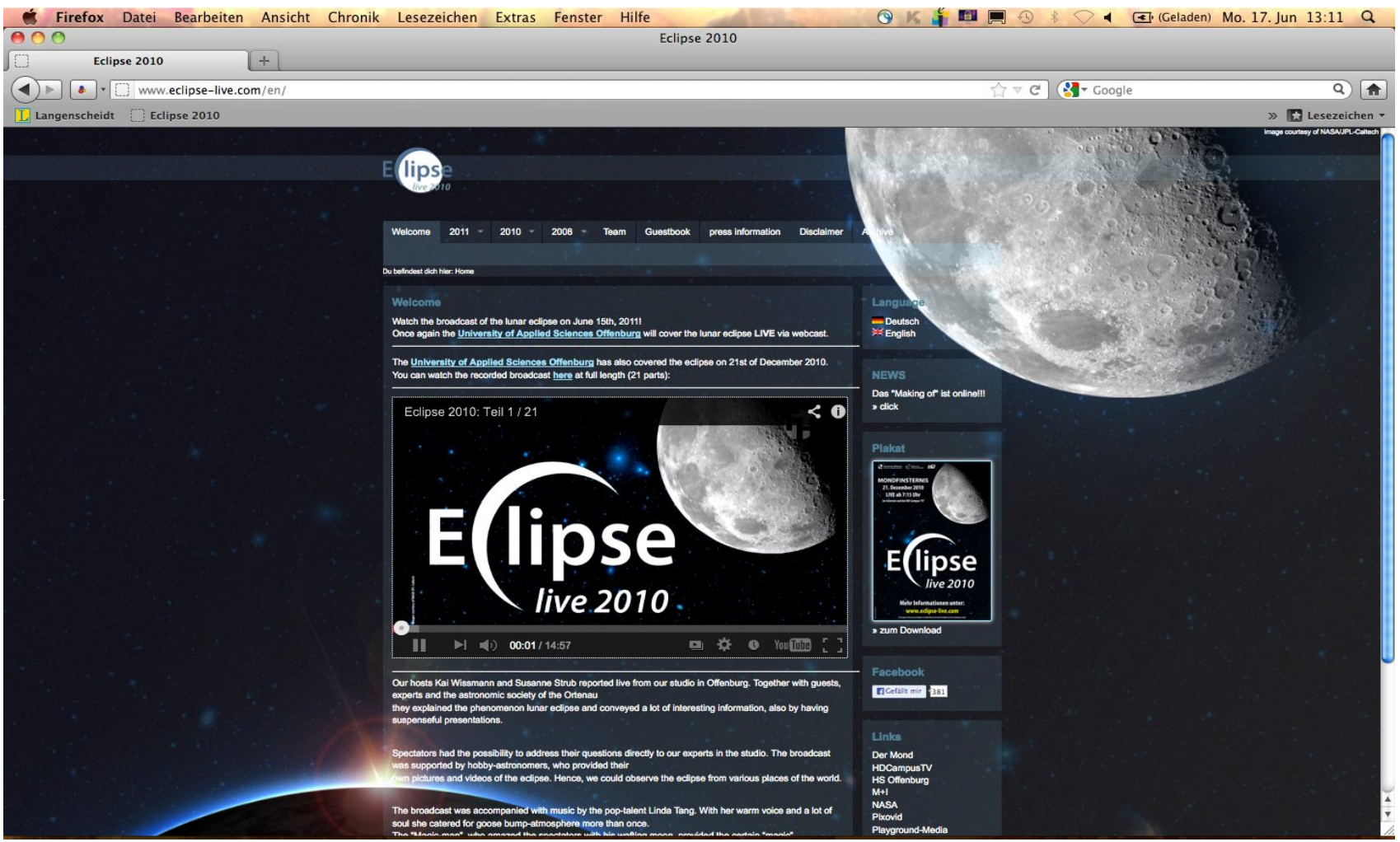

Figure 10.a: Eclipse-live website
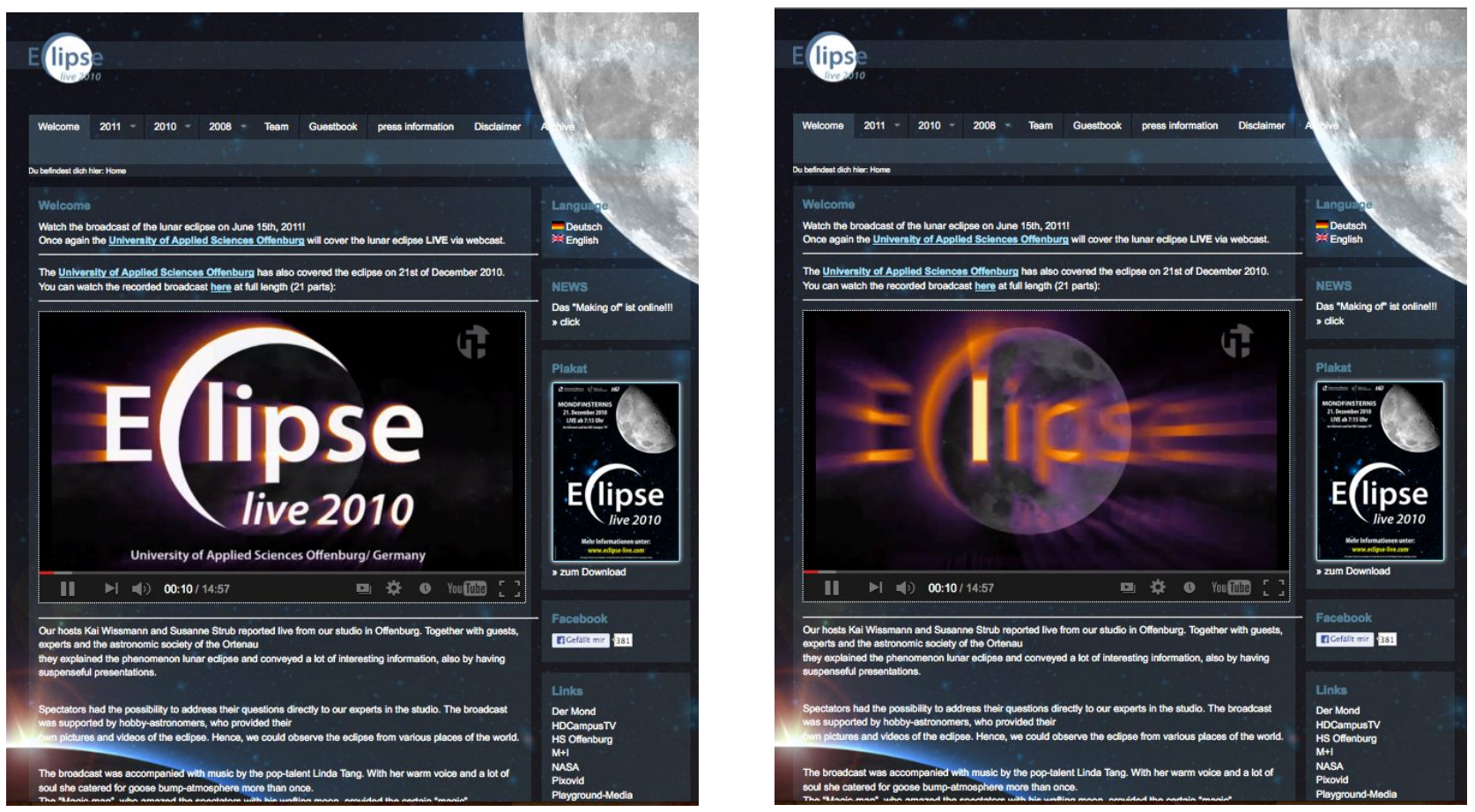

Figure 10.b-c: Intro for live broadcasting at www.eclipse-live.com

Proc. of SPIE Vol. 9289 928909-11 


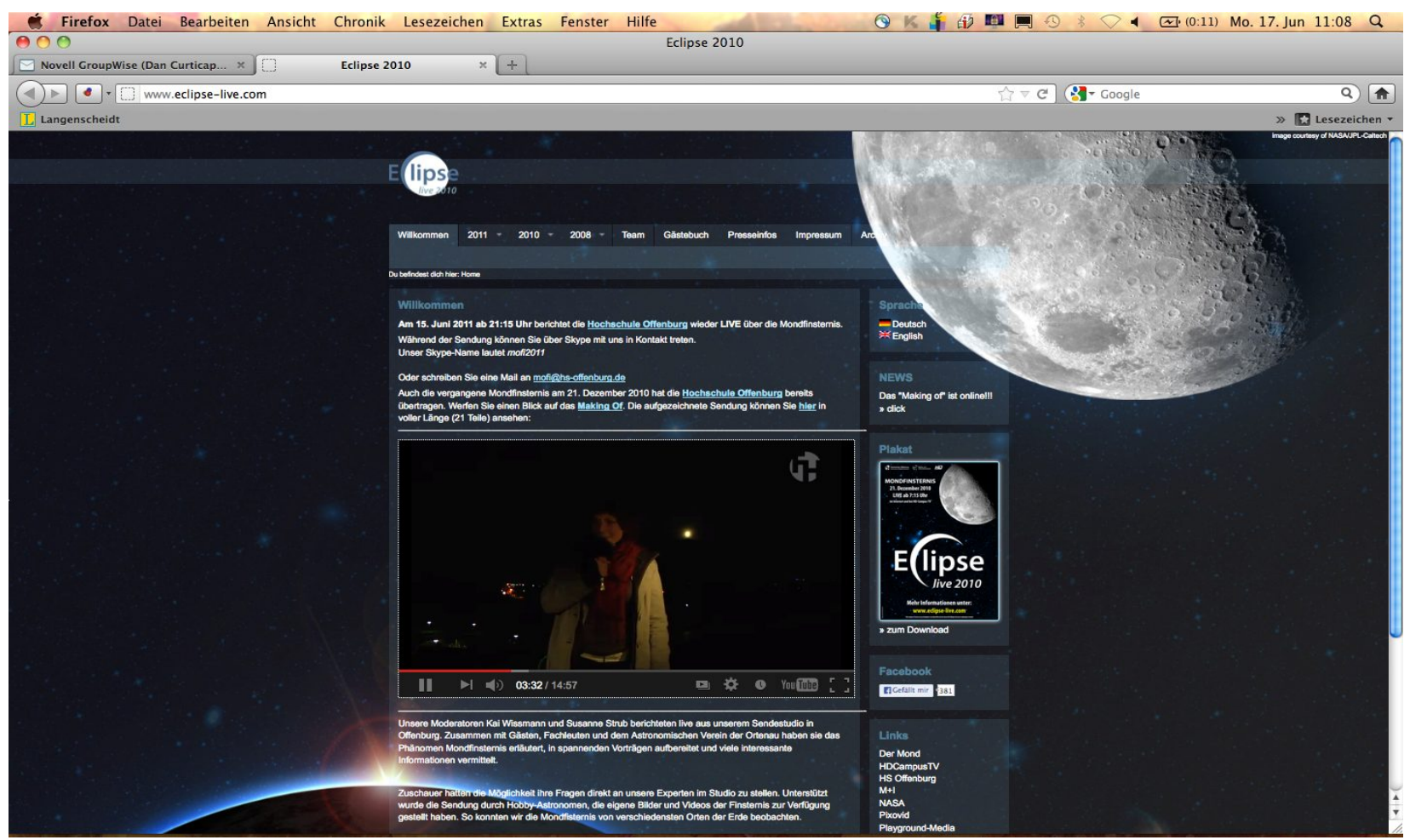

Figure 11.a: Live broadcasting switch to the roof camera during the lunar eclipse - moderator;

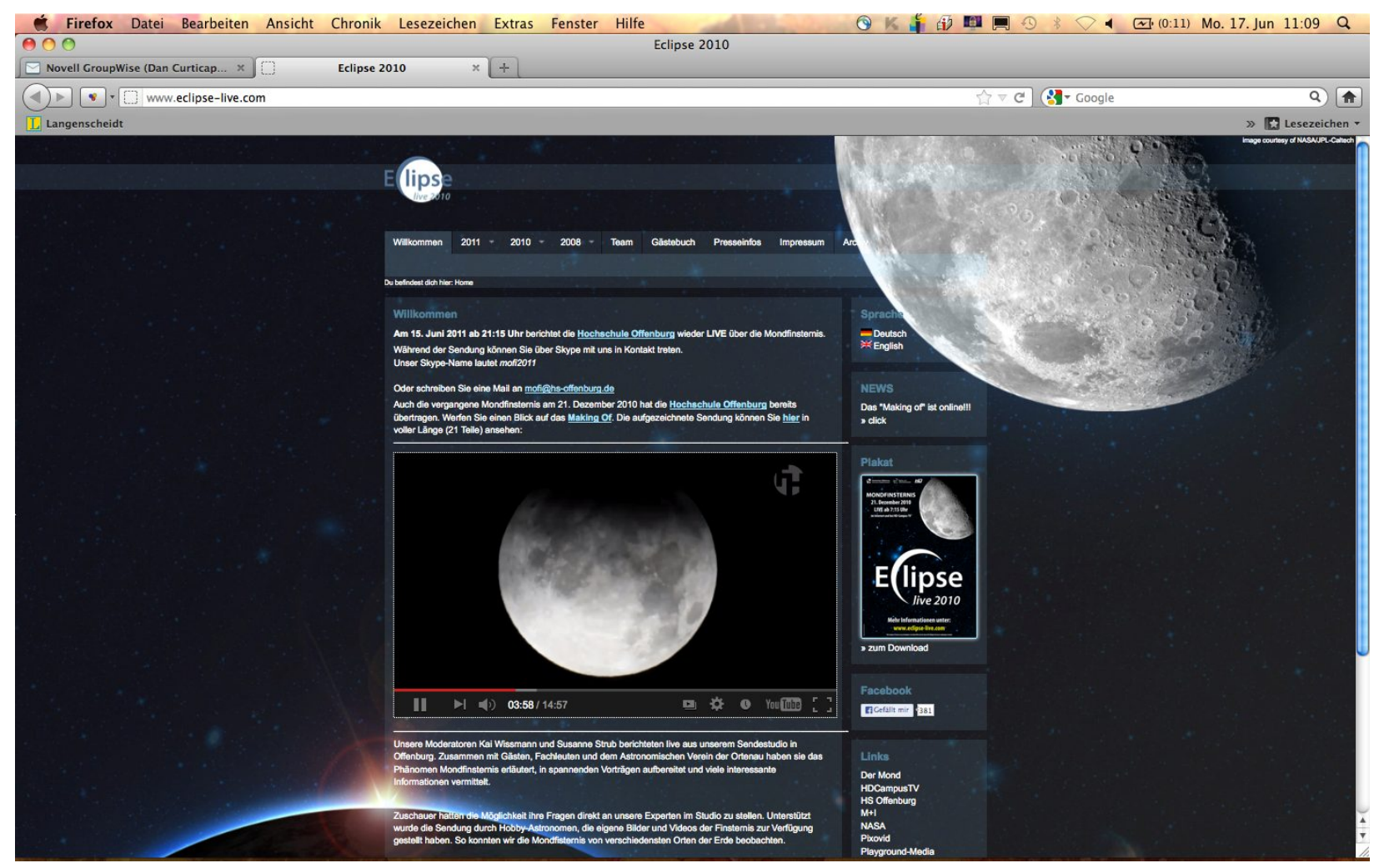

Figure 11.b: Live broadcasting switch to the roof camera during the lunar eclipse - Eclipsed moon view

Proc. of SPIE Vol. 9289 928909-12 


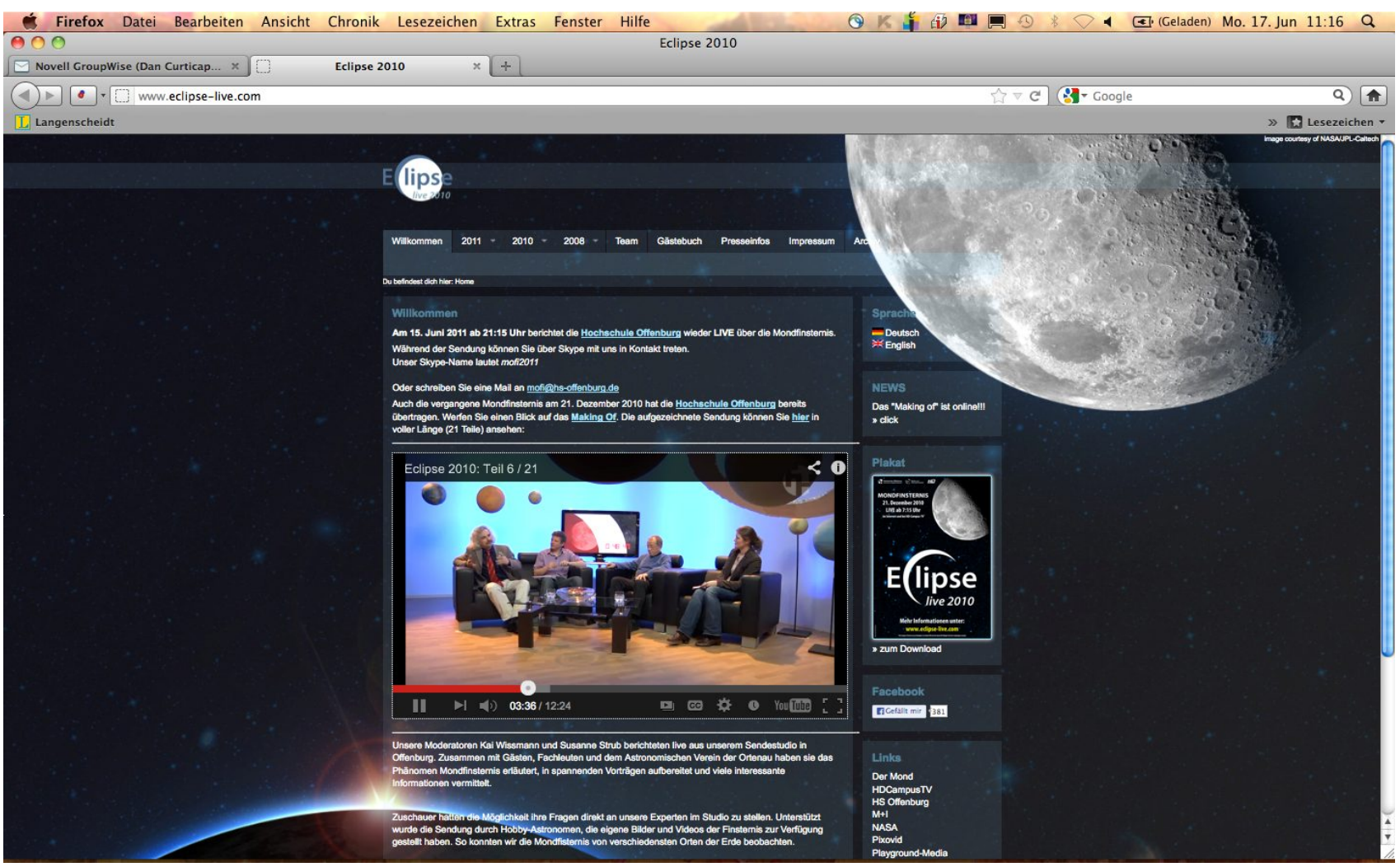

Figure 12a: Live Broadcasting studio - overview;
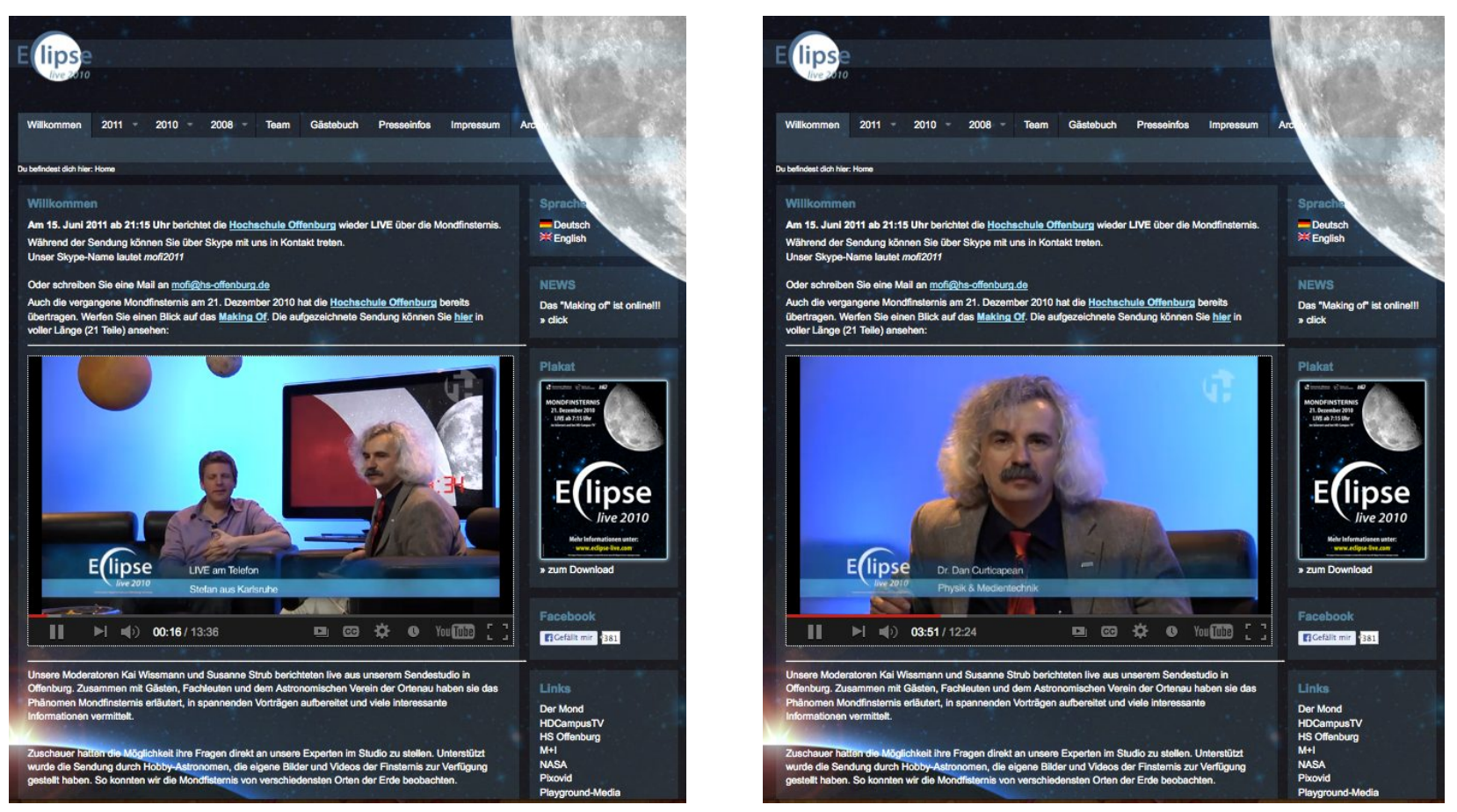

Figure 12.b-c: Live Broadcasting studio - Answering live questions about lunar eclipses

Proc. of SPIE Vol. $9289928909-13$ 


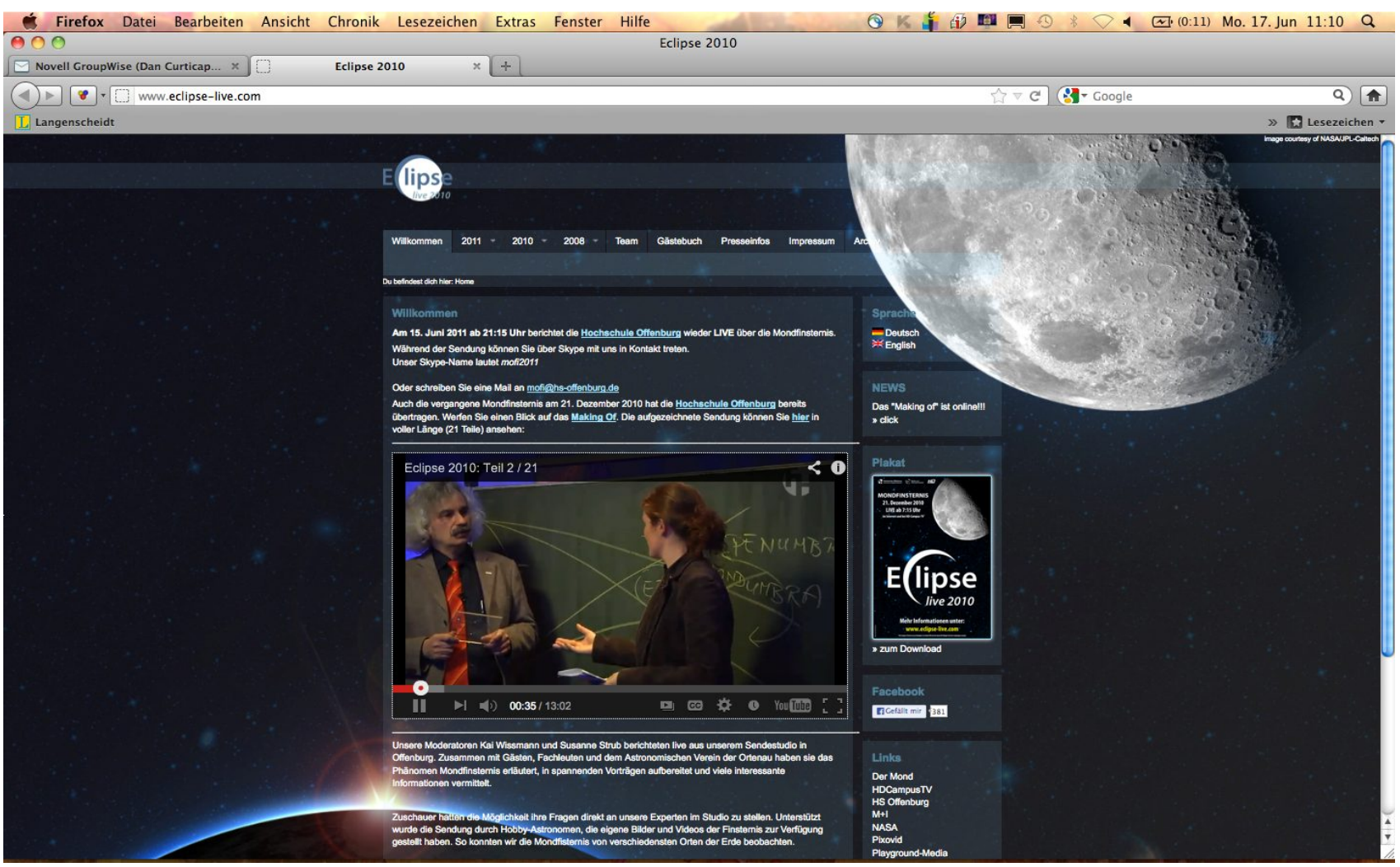

Figure 13.a: Live broadcasting, theoretical presentation - Umbra and penumbra considerations
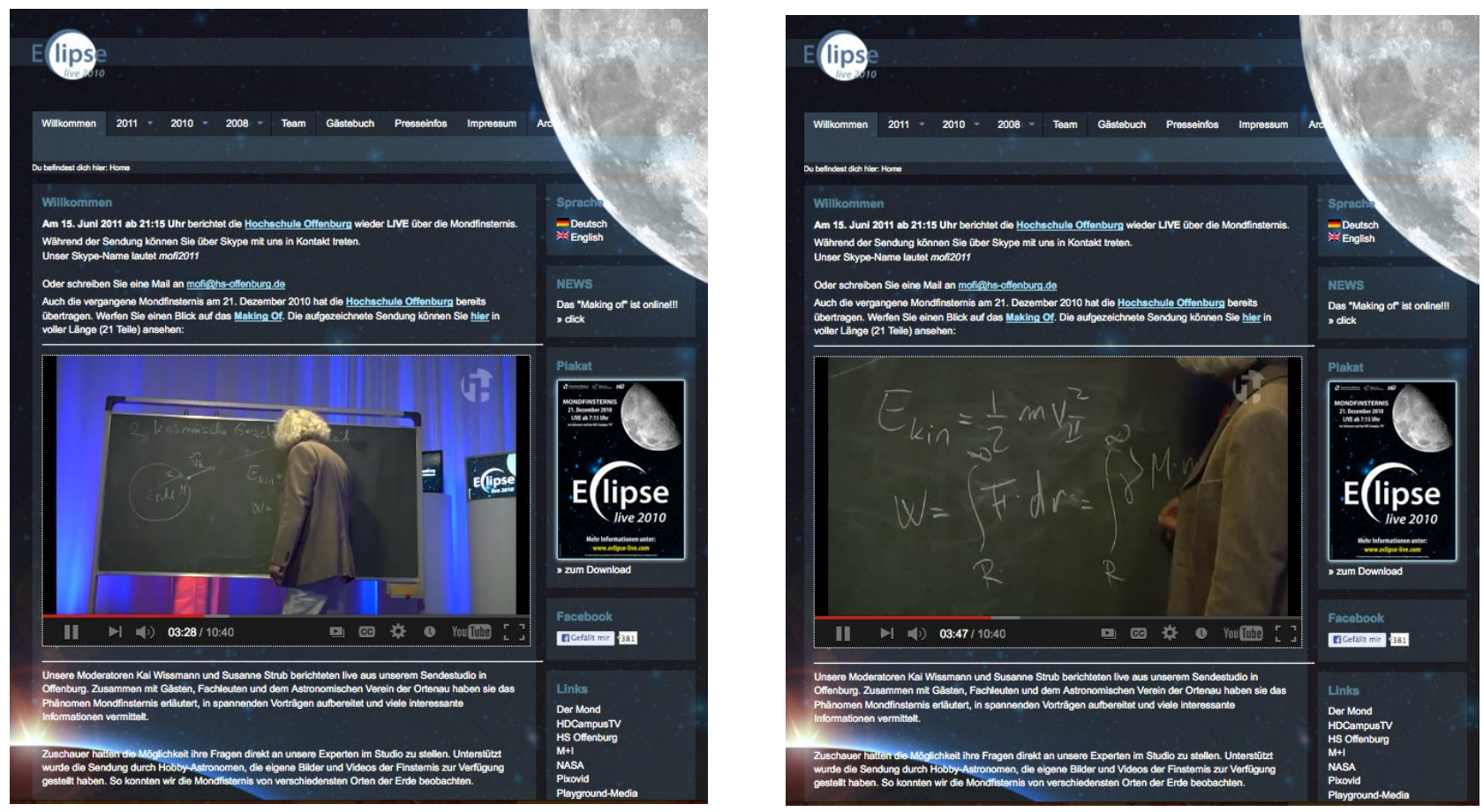

Figure 13.b-c: Live broadcasting, theoretical presentation - Computation of cosmic velocities

Proc. of SPIE Vol. 9289 928909-14 


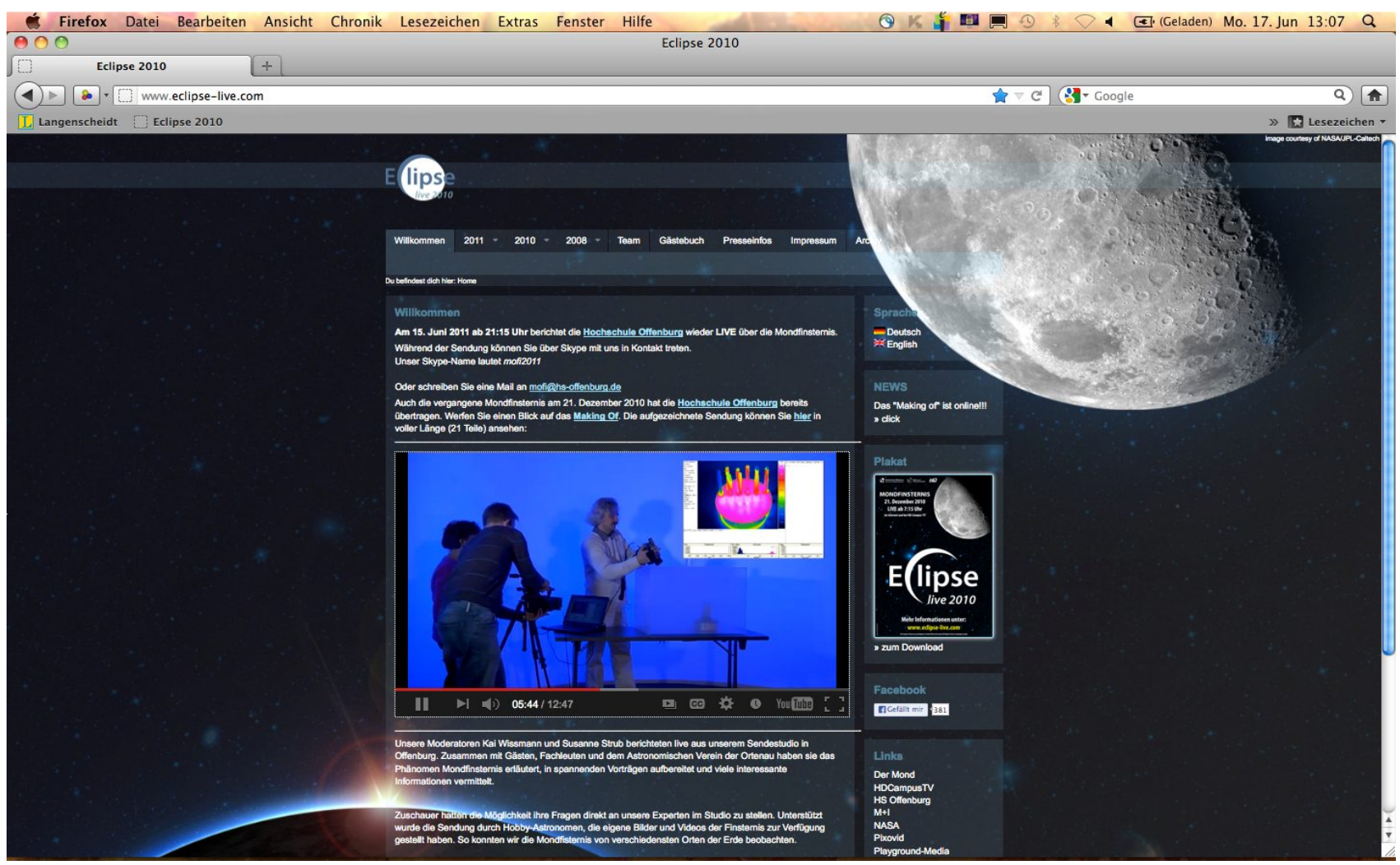

Figure 14.a: Experiment to understand IR astronomy - Film footage
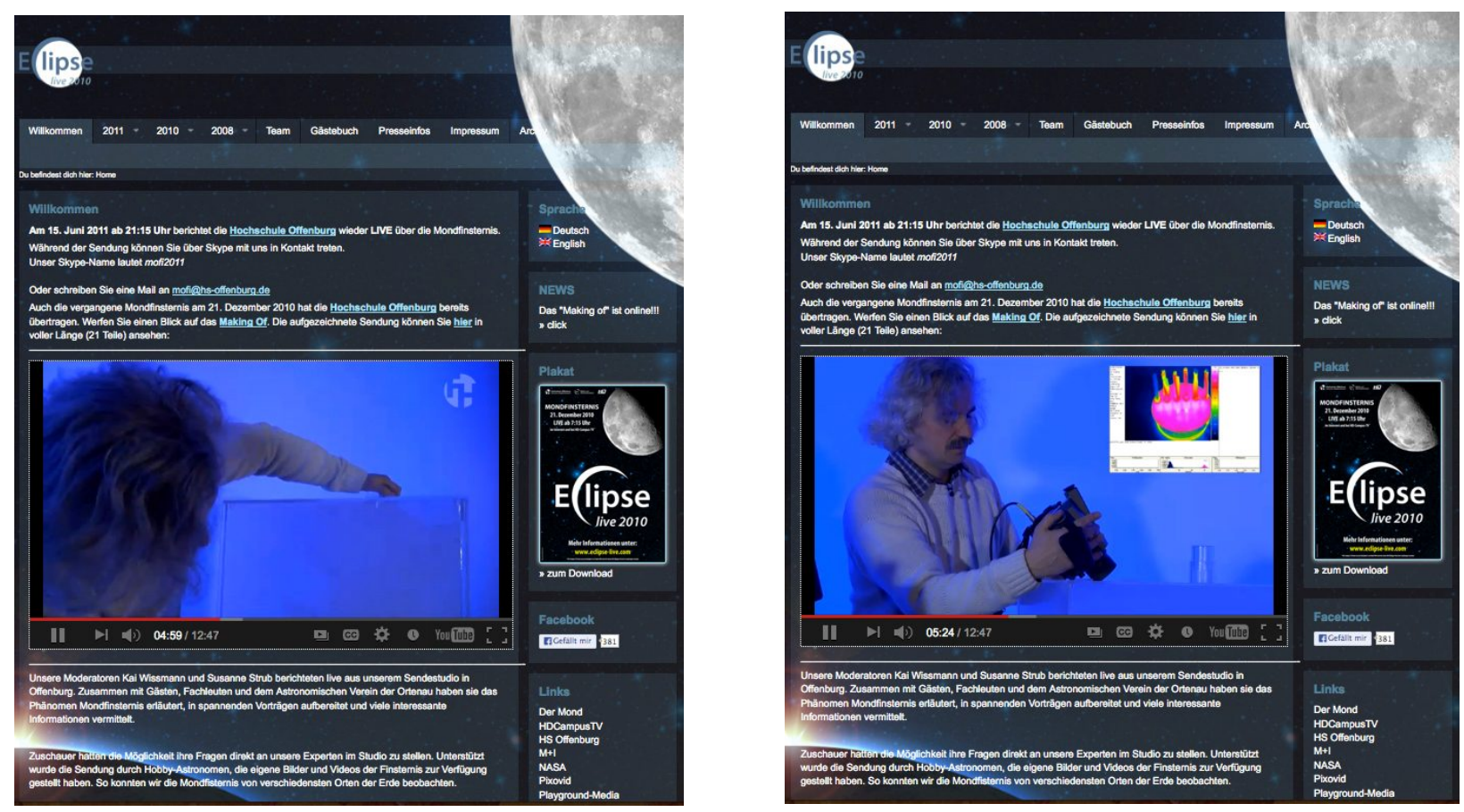

Figure 14.b-c: Experiment to understand IR astronomy - Film footage

Proc. of SPIE Vol. 9289 928909-15 


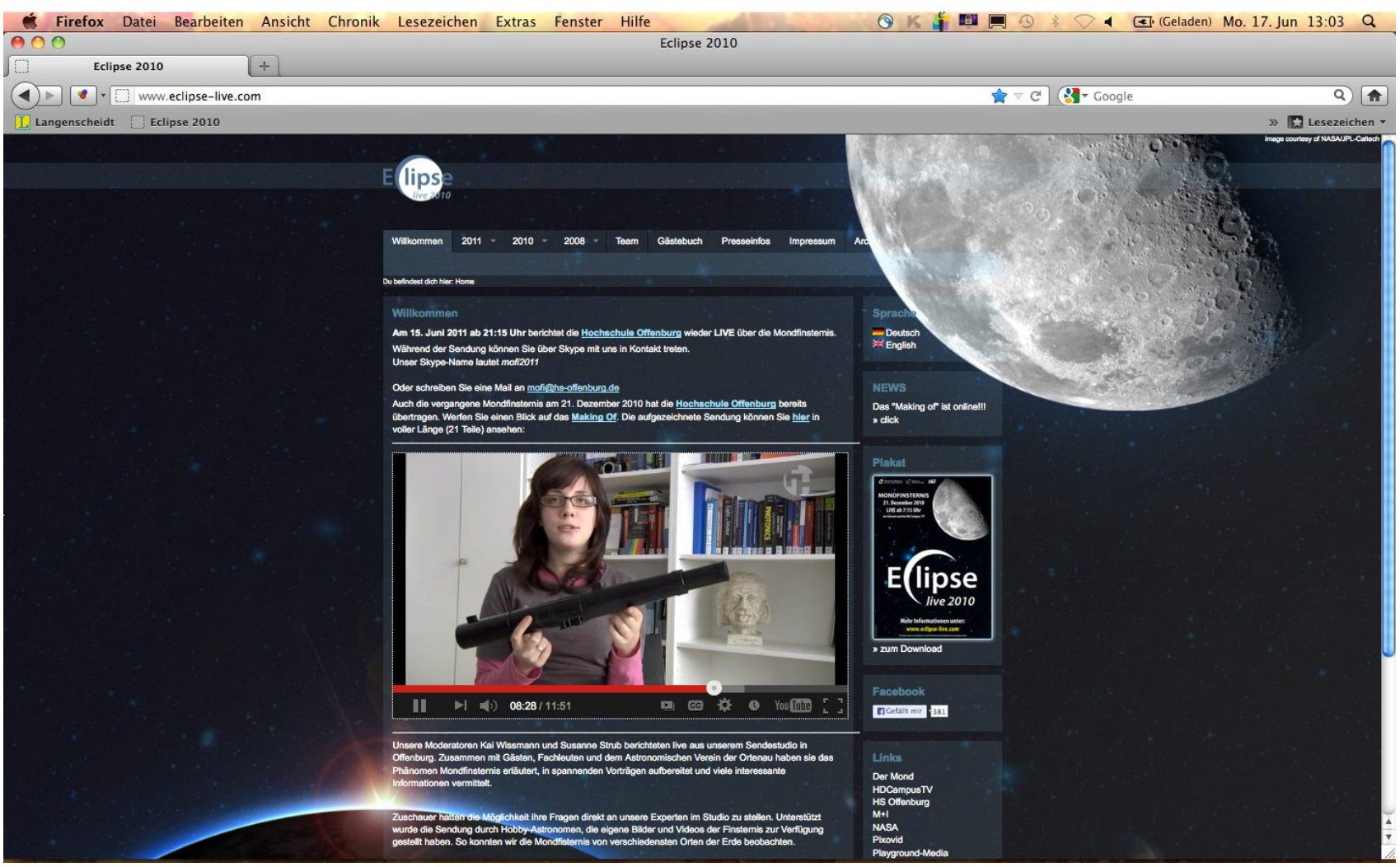

Figure 15.a: Galileoscope - Film footage

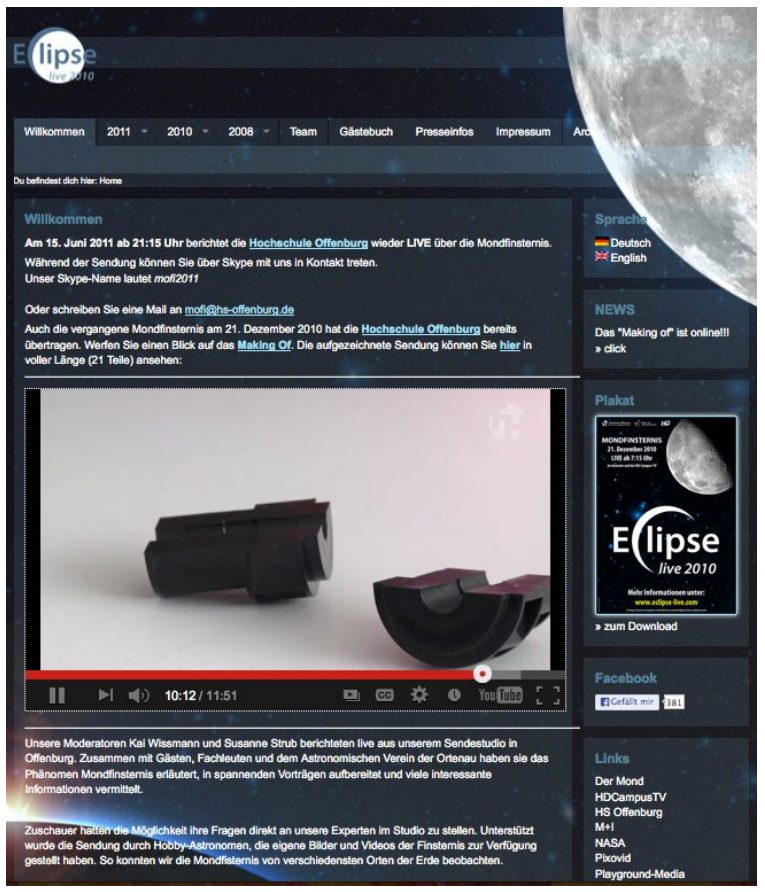

Figure 15.b: Galileoscope - ocular

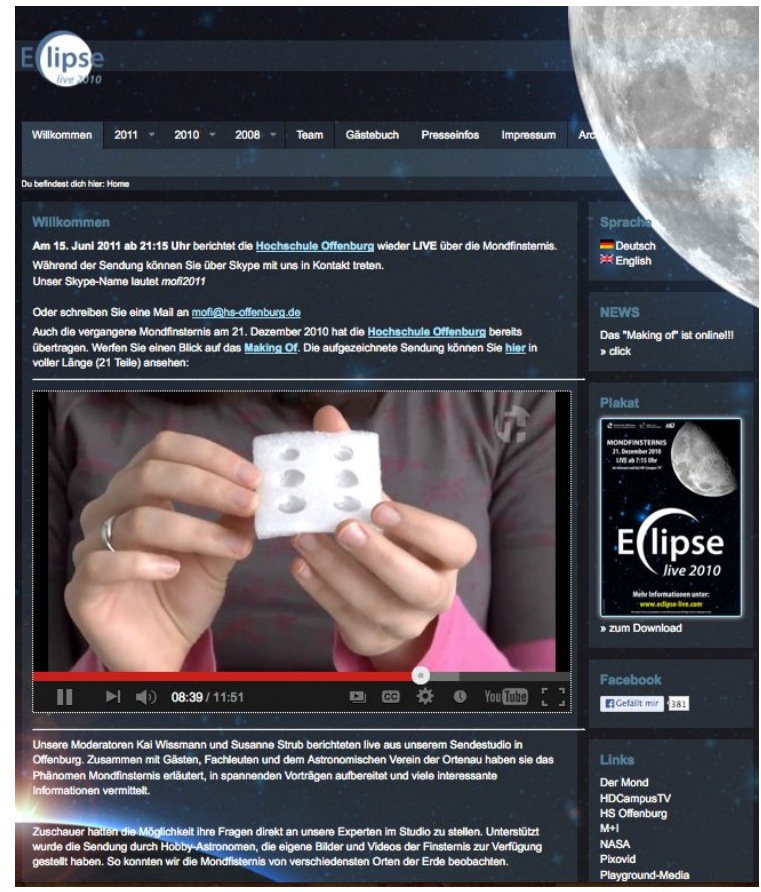

Figure 15.c: Galileoscope - lens

Proc. of SPIE Vol. 9289 928909-16 